\title{
Effect of weekly vitamin D supplements to Indian low birth weight term infants on mortality, morbidity, and growth in the first 6 months of life: a randomised controlled trial
}

\author{
G. T. Kumar ${ }^{1}$, H. P. S. Sachdev ${ }^{2}$, H. Chellani ${ }^{3}$, A. M. Rehman ${ }^{4}$, V. Singh ${ }^{1}$, H. Arora ${ }^{1}$ and S. Filteau $^{4}$ \\ ${ }^{1}$ Institute of Home Economics, Delhi University, New Delhi, India, ${ }^{2}$ Sitaram Bhartia Institute of Science and Research, \\ New Delhi, India, ${ }^{3}$ Safdarjung Hospital, New Delhi, India and ${ }^{4}$ London School of Hygiene and Tropical Medicine, \\ Keppel Street, London WC1E 7HT, UK
}

Poor vitamin D status has been associated with impaired immune function and resistance to infections ${ }^{(1-3)}$. However, there is little data from randomised trials investigating whether vitamin D supplementation can improve health of groups at high risk of infection such as low birth weight infants in low-income countries.

We conducted a randomised controlled trial of weekly vitamin D supplements for 6 months at a dose of one recommended dietary allowance per day $(35 \mu \mathrm{g} / \mathrm{week})$ to 2079 Indian low birth weight term neonates. Inclusion criteria were singleton infant, $<48 \mathrm{~h}$ old, birth weight $1.8-<2.5 \mathrm{~kg}$, gestational age $>37$ weeks, no congenital abnormalities, resident within $15 \mathrm{~km}$ of the study hospital, parental informed consent. Infants were visited weekly at home for observed supplementation and came monthly to the clinic for clinical examination and anthropometry. The primary outcome was hospitalisation or death during the first 6 months of life and the key secondary outcome was growth. Vitamin D status was assessed in a subsample $(20 \%)$ of the infants. The trial was registered as NCT00415402 on Clinicaltrials.gov.

There was no statistically significant difference between treatment groups in death plus hospitalisation (ninety-two hospitalisations or deaths in the vitamin D group and ninety-nine in the placebo group; adjusted rate ratio $0.98(95 \% \mathrm{CI} 0.70,1.38) ; P=0.92)$, or referral to outpatient clinic for moderate morbidity. Vitamin D supplementation resulted in better vitamin D status as assessed by plasma 25-hydroxyvitamin D at 6 months. In adjusted analyses, vitamin D treatment significantly increased standard deviation $(Z)$ scores at 6 months for weight, length and arm circumference, and decreased the proportion of children stunted (length-for-age $Z<-2$ ) or with arm circumference $Z$ score $<-2$.

A weekly dose of vitamin D resulted in better vitamin D status and benefited the classical vitamin D function of bone growth but did not decrease the incidence of severe morbidity or death among young breast-fed infants.

Effect of vitamin D supplementation on plasma 25-hydroxy-vitamin D (25OHD) at 6 months.

\begin{tabular}{lllr}
\hline & Vitamin D group $(n$ 216) & Placebo group $(n$ 237) & $P$ \\
\hline Mean 25OHD $(\mathrm{ng} / \mathrm{ml})$ & $22.0($ sD 9.0) & $14.4($ sD 10.2) & $<0.001$ \\
Proportion low 25OHD $(<20 \mathrm{ng} / \mathrm{ml})$ & $94(43.5 \%)$ & $174(73.4 \%)$ & $<0.001$ \\
Weight-for-age $Z$ & $-1.51($ sD 0.98, $n$ 627) & $-1.60($ SD 0.98, $n$ 646) & 0.026 \\
Length-or-age $Z$ & $-1.84($ sD 0.98, 620) & $-1.95($ sD 0.99, 638) & 0.014 \\
\hline
\end{tabular}

The trial was funded by Department of Biotechnology, Ministry of Science and Technology, Government of India; Nutrition Third World; Sight and Life.

1. Roth DE, Shah R, Black RE et al. (2010) Acta Paediatr 99, 389-393.

2. Laaksi I, Ruohola JP, Tuohimaa P et al. (2007) Am J Clin Nutr 86, 714-717.

3. Gibney KB, MacGregor L, Leder K et al. (2008) Clin Infect Dis 46, 443-446. 